\title{
Preliminary Study on the Performance of Two Chemistry Classes Subjected to Self-recorded Videos and Traditional Face-to-face Learning
}

\author{
D.O.I - 10.51201/Jusst12636 \\ http://doi.org/10.51201/Jusst12636 \\ Mee Yoke Chong*,1, Evyan YCY ${ }^{2}$ \\ ${ }^{1}$ Center for American Education, INTI International University, Persiaran Bandar BaruNilai, 71800 \\ Nilai, Malaysia \\ ${ }^{2}$ School of Applied Sciences, Faculty of Engineering, Science and Technology, Nilai University, \\ Persiaran Bandar BaruNilai, 71800 Nilai, Malaysia
}

\begin{abstract}
Nowadays, most of the educators in higher institutions adopt videos in their subjects as a powerful teaching tool. The educators integrate video into the teaching of analytical, instrumental and organic laboratory classes aside from other teaching tools such as case study and flipped classroom. The adoption of video as a teaching tool is inspired by their inability to apply it to the real-life owing to the ambiguity on the chemistry concepts among the undergraduate students. Also, it creates an active learning environment among the undergraduate students. Therefore, a preliminary study is conducted to compare the effect of self-recorded chemistry educational videos and the traditional face-to-face learning. The comparison is investigated on the performance of two classes of Chemistry students at INTI International University, by measuring the percent of correctness. In conclusion, based on the preliminary study, the use of self-recorded videos by the instructor is evidently enhance the performance of the class of students. Therefore, further research will be conducted to validate the hypothesis.
\end{abstract}

Keywords: Active learning, chemistry class, face-to-face, percent of correctness, self-recorded videos

\section{Introduction}

The use of information and communication technologies (ICT) in teaching a Chemistry subject is blooming since 1980's [1]. The approach is motivated by the students' wrong concepts in chemistry that compel them to memorize it rather than learning [2-3]. The problem needs to be solved because it obstructs them to learn more and independently [4]. Besides, the use of ICT is able to strengthen the student's mental model individually [5]. This is because the students are able to store a concept upon understanding, which enables them to relate it to the real-life phenomena [6]. Moreover, the implementation of ICT in educational environment enables the switch from teacher-centered learning (face-to-face in the classroom) to student-centered learning (i.e. collaborative learning) [7]. The 
students interact with peers actively after watching the presented technological tools (i.e. television, video-taped, animation, simulation, videos, internet sources information, power point presentation and etc.) by their instructor [8]. In fact, the students will discuss the chemical phenomenon, explain the chemical concepts, exchange views and build a body of common knowledge among their peers [9].

Generally, video playing is one of the teaching tools which attracts the attention of instructors vastly owing to its virtue in delivering the instructions [10]. The advantages of video playing are:

(a) it enables the students with language issue to learn leisurely because the students can pause, slowdown and repeat the portions [11-12].

(b) it decreases the students learning time on the laboratory skills [11].

(c) it stimulates the students to produce video which serves as a proof of their remarkable understanding [11].

(d) it enables the students to capture rare and hard-to-duplicate material and phenomena in order to solve higher order thinking skills questions. Also, it promotes higher degree of satisfaction upon attaining the knowledge [13-16].

(e) it is cost effective by overcoming the resource shortage in access and support for laboratory course experiences [14-17].

(f) it is a platform to explain the concepts for distance education programs [18].

[19] implemented flipped classroom successfully with the aid of the ICT tools. The "Flipped classroom" model, a new teaching tool, is also known as "inverted classroom" in which the role of an instructor has been switched with the students. The students will read the material provided by the instructor at home instead of learning it from their instructor in the class. Subsequently, the students are exposed to the active learning activities in the class. [20] uploaded online video for college chemistry preparatory course students prior to the problem solving activities in the class. Based on the Student Assessment of their Learning Gains (SALG) survey and student course evaluations, the results showed that the flipped classroom students obtained higher final exam scores and overall success in the class compared to the standard lecture-based students. This is because it attracts attention of the students and the students felt less intimidated by chemistry.

Nevertheless, video playing has been extensively explored in teaching skills and instrumental techniques of organic and analytical laboratory classes, respectively [11]. Researchers found that students provided with laboratory instructional videos prior to the laboratory session are more independent. The fact is in well agreement with the work conducted by [17]. The results show that the students who watched the videos before the laboratory session completed their experiments in a short time. In conclusion, watching the demonstration via videos boosts the students understanding and confidence by seeking deeper chemistry learning opportunities [17].

On top of that, the implementation of videos via online, web-based and animation were attempted by the researchers in teaching analytical chemistry, chair \& boat conformation in organic chemistry and particulate nature of matter in general chemistry [6,14,21]. The posting of videos as a supplementary in teaching tool is undoubtedly useful for the students at any level.

However, self-recorded video was chosen in this study owing to its unique features over online videos that are: 
(a) self-recorded video is more compact and concise compared to the video available online which is lengthy (40 minutes or longer). The longer duration video prohibits the students from focusing on the informative content [22].

(b) the students do not experience playback delays and long buffering interval because of network congestion and thus it preserves the student's curiosity [23].

(c) the content of the self-recorded video meets the course learning outcomes of the subject matter and hence reduces the contradiction with the reading materials (i.e. power point slides and text book) [24].

(d) the language used in the self-recorded videos are easy to understand compared to the video available online due to difference in terms and vocabularies used [25].

(e) the time taken to prepare self-recorded video is shorter than the time taken to search for an appropriate video [14]. Therefore, a study has been conducted to investigate the impact of selfrecorded videos on the students' performance.

\section{Methodology}

\subsection{Participants}

The participants of this study were 36 students enrolled into a four-credit-hour General Chemistry, Lab II course for Bachelor of Biotechnology program before proceed to Biochemistry I course. The prerequisite for this course is a student has to pass General Chemistry, Lab I, with at least a C. Students enrolled in the course are required to attend 2 hours of lecture, 1 hour of tutorial, 1 hour of online learning and 2 hours of laboratory session per week. A class of 16 students in section 1A were subjected to 4 self-recorded videos by the instructor whereas another class of 20 students from section 1T1 were subjected to traditional face-to-face learning. At the end of the semester, these groups of students were given written test during final examination.

\subsection{Procedure}

The instructor identified 4 topics for both online learning (self-recorded videos by the instructor) and traditional face-to-face learning. The topics chosen were half-life calculation from chapter 1 (Nuclear chemistry), the strength and color of complex ions from chapter 4 (Transition metals), free radical mechanism of alkanes from chapter 7 (Reactions of alkanes) and oxidation of alcohols from chapter 10 (Reactions of alcohols). Video 1 was related to the calculation of half-life and the activity of a radioactive after a period of time. The formulas introduced in the self-recorded videos were $k=\frac{\ln 2}{t_{1 / 2}}$ and $\ln \frac{A_{t}}{A_{o}}=-k t$; where $\mathrm{k}=$ decay constant of the radioactive, $\mathrm{t}_{1 / 2}$ is the half-life of the radioactive, $\mathrm{A}_{\mathrm{t}}=$ the remaining amount of radioactive after time, $\mathrm{t}$ and $\mathrm{A}_{\mathrm{o}}=$ the initial amount of radioactive. Video 2 was related to the color of the complex compounds and the effect of ligands towards it's color. Also, the students were exposed to the spectrochemical series and color wheel in the video. Video 3 was pertaining to the free radical substitution of alkane with the presence of halogen and heat to produce haloalkane. In this video, students were exposed to the mechanism of free radical substitution that consists of three steps, namely initiation, propagation and termination. Video 4 was on the oxidation of 
alcohols. Theoretically, both primary and secondary alcohols were oxidized to carboxylic acids and ketones by acidified potassium dichromate (VI) which cause a change from orange to green. In video 4 , the students were able to connect the experiment conducted with the theory learnt. The self-recorded videos were prepared by using $i$-studio and the duration for each video was lesser than 6 minutes. The size of each video is lesser than $5 \mathrm{MB}$. These videos will be uploaded to the Blackboard weekly along with the online quizzes. The students were required to watch the video and answer the online quizzes within a week. Feedback will be provided to the students after the due date of submission. At the end of the semester, these group of students will sit for their final examination. The percentage of correctness obtained by each student on the specific exam questions were calculated.

\section{Results and discussions}

Table 1 summarizes the student's performance upon exposure to traditional face-to-face learning and online learning. The students subjected to self-recorded video 1 obtained lower mean of percent correctness (35.00 percent) compared to the students exposed to the traditional face-to-face lecture (60.00 percent). It shows that the students achieved better results in calculation question via traditional face-to-face along with small standard deviation of 39.44 percent. The use of self-recorded video on calculation question can be improved by adding detailed explanation for better understanding amongst the students [26]. Also, the group of students subjected to self-recorded video by the instructor obtained low mean percent of correctness due to the student's first time exposure to this method of teaching [27]. The students were shocked with the change and they need some time to adapt with the new learning environment. On the other hand, both groups obtained same mean value of 90.00 percent of correctness after watched self-recorded video 2. The results signified that the learning outcome based on theory is suitable for both face-to-face traditional lecture and self-recorded video. However, the variation of marks by the students exposed to face-to-face traditional lecture is smaller with standard deviation of 22.50 percent. This is because in the traditional face-to-face learning, the instructor ensures each student grab the concept in the class whereas the students learned through selfrecorded videos depends on their discipline and attitude. It is worth to mention that self-recorded video teaching tool is found to be helpful to the students in understanding mechanism questions as mentioned by [28]. The concept is in good agreement with the results obtained in this study. This was because the students watched video 3 possessed mean of 66.11 percent correctness and standard deviation of 24.35 percent whereas the students learned via traditional face-to-face portrayed mean and standard deviation of 46.67 percent correctness and 50.18 percent correctness, respectively. This can be explained that students need more time to grasp and understand the mechanism concept. Additionally, the students learned via self-recorded video 3 were more flexible as they can learn without restriction to the class time limitation and attention due to the tiredness after attending many lectures per day [29]. In a likely manner, the self-recorded video tool is found to be benefitting the students with simple organic reaction question. The students watching video 4 obtained mean of 85.00 percent correctness along with 35.75 percent standard deviation whereas the students learned via traditional face-to-face learning obtained mean of 60.00 percent correctness and standard deviation of 51.64 percent correctness. 
Table 1: Comparison of students' performance subjected to self-recorded videos and traditional faceto-face learning.

\begin{tabular}{|c|c|c|c|c|c|c|}
\hline \multirow[t]{2}{*}{ Videos } & \multirow[t]{2}{*}{$\begin{array}{c}\text { Duration } \\
\text { (min) }\end{array}$} & \multirow[t]{2}{*}{$\begin{array}{c}\text { Size } \\
\text { (MB) }\end{array}$} & \multicolumn{2}{|c|}{$\begin{array}{l}\text { Traditional face- } \\
\text { to-face learning } \\
\text { (\% correctness) }\end{array}$} & \multicolumn{2}{|c|}{$\begin{array}{c}\text { Self-recorded videos } \\
\text { by instructor } \\
\text { (\% correctness) }\end{array}$} \\
\hline & & & Mean & $\begin{array}{l}\text { Standard } \\
\text { deviation }\end{array}$ & Mean & $\begin{array}{l}\text { Standard } \\
\text { deviation }\end{array}$ \\
\hline 1 (Chapter 1) & 2.13 & 8.96 & 60.00 & 39.44 & 35.00 & 39.44 \\
\hline 2 (Chapter 3) & 3.11 & 12.90 & 90.00 & 22.50 & 90.00 & 31.62 \\
\hline 3 (Chapter 7) & 2.30 & 9.21 & 46.67 & 50.18 & 66.11 & 24.35 \\
\hline 4 (Chapter 10) & 2.04 & 26.60 & 60.00 & 51.64 & 85.00 & 35.75 \\
\hline Total & & & 65.56 & 25.63 & 66.43 & 15.17 \\
\hline
\end{tabular}

In short, the utilization of self-recorded videos is an added tool in teaching general chemistry. It is able to assist the students in understanding the chemistry concepts. This was because the students learned from self-recorded videos obtained higher percent correctness in their final examination and the mean per cent correctness improved gradually. The overall mean and standard deviation obtained by the students subjected to the self-recorded videos are 66.43 percent correctness and 15.17 percent, respectively. On the contrary, the overall mean and standard deviation obtained by students subjected to the traditional face-to-face are 65.56 percent correctness and 25.63 percent, respectively. The approach of self-recorded videos as an alternative tool in teaching can be tried out by the instructors in the higher private institution because it helps the students. In fact, it reduces the redundancy of repeating the lecture for the absentees (with or without valid reason) [30].

\section{Conclusions}

In conclusion, the introduction of self-recorded videos improved the student's performance in general chemistry course by obtaining higher mean of 66.43 per cent correctness consistently with lower standard deviation of 15.17 per cent compared to the control group. Self-recorded videos by the instructor can be an alternative tool to assist the students' learning ability. The study has to be implemented extensively on huge number of students along with more topics.

\section{Acknowledgement}

The authors would like to thank Teaching \& Learning Center, Faculty of Health \& Life Sciences and Examinations Center, INTI International University, Nilai for their technical support. 


\section{References}

[1] B. Pekdağ, "Alternative methods in learning chemistry: Learning with animation, simulation, video and multimedia," Journal of Turkish Science Education., 2010, pp. 111-118.

[2] N. Mansoor, M. A. RODRÍGUEZ, "Do we have to introduce history and philosophy of science or is it already 'inside'chemistry?," Chemistry Education Research and Practice., 2001, pp. 159-164.

[3] J. Othman, D. F. Treagust, A. Chandrasegaran, “An investigation into the relationship between students' conceptions of the particulate nature of matter and their understanding of chemical bonding," International Journal of Science Education., 2008, pp. 1531-1550.

[4] M. J. Sanger, A. J. Phelps, J. Fienhold, "Using a computer animation to improve students' conceptual understanding of a can-crushing demonstration," Journal of Chemical Education., 2000, pp. 1517.

[5] D. Clark, D. Jorde, "Helping students revise disruptive experientially supported ideas about thermodynamics: Computer visualizations and tactile models," Journal of Research in Science Teaching: The Official Journal of the National Association for Research in Science Teaching., 2004, pp. 1-23.

[6] A. Velázquez-Marcano, V. M. Williamson, G. Ashkenazi, R. Tasker, K. C. Williamson, “The use of video demonstrations and particulate animation in general chemistry," Journal of Science Education and Technology.. 2004, pp. 315-323.

[7] L. Benedict, H. E. Pence, "Teaching chemistry using student-created videos and photo blogs accessed with smartphones and two-dimensional barcodes," Journal of Chemical Education., 2012, pp. 492-496.

[8] W. S. Harwood, M. M. McMahon, "Effects of integrated video media on student achievement and attitudes in high school chemistry," Journal of Research in Science Teaching: The Official Journal of the National Association for Research in Science Teaching., 1997, pp. 617-631.

[9] R. Driver, H. Asoko, J. Leach, P. Scott, E. Mortimer, "Constructing scientific knowledge in the classroom,” Educational Researcher., 1994, pp. 5-12.

[10] R. E. Clark, "Reconsidering research on learning from media," Review of Educational Research., 1983, pp. 445-459.

[11] J. T. Jordan, M. C. Box, K. E. Eguren, T. A. Parker, V. M. Saraldi-Gallardo, M. I. Wolfe, M. T. Gallardo-Williams, "Effectiveness of student-generated video as a teaching tool for an instrumental technique in the organic chemistry laboratory," Journal of Chemical Education., 2015, pp. 141-145.

[12] O. F. Vural, "The Impact of a Question-Embedded Video-based Learning Tool on E-learning," Educational Sciences: Theory and Practice., 2013, pp. 1315-1323.

[13] J. Enger, "Teaching Introductory Chemistry with Videocassette Presentations," 1976.

[14] Y. He, S. Swenson, N. Lents, "Online video tutorials increase learning of difficult concepts in an undergraduate analytical chemistry course," Journal of Chemical Education., 2012, pp. 1128-1132.

[15] M. Kearney, D. F. Treagust, "Constructivism as a referent in the design and development of a computer program using interactive digital video to enhance learning in physics," Australasian Journal of Educational Technology., 2001, pp. 64 - 79.

[16] W. C. Savenye, E. Strand, "Teaching Science Using Interactive Videodisc: Results of the Pilot Year Evaluation of the Texas Learning Technology Group Project," 1989. 
[17] L. S. Nadelson, J. Scaggs, C. Sheffield, O. M. McDougal, "Integration of video-based demonstrations to prepare students for the organic chemistry laboratory," Journal of Science Education and Technology., 2015, pp. 476-483.

[18] D. Zhang, L. Zhou, R. O. Briggs, "Nunamaker Jr JF. Instructional video in e-learning: Assessing the impact of interactive video on learning effectiveness," Information \& Management., 2006, pp. 15-27.

[19] C. F. Herreid, N. A. Schiller, "Case studies and the flipped classroom," Journal of College Science Teaching., 2013, pp. 62-66.

[20] K. W. Ruddick, "Improving chemical education from high school to college using a more hands-on approach," The University of Memphis., 2012.

[21] J. Tierney, M. Bodek, S. Fredricks, E. Dudkin, K. Kistler, "Using web-based video as an assessment tool for student performance in organic chemistry," Journal of Chemical Education., 2014, pp. 982-986.

[22] E. Goldstein, "Cognitive psychology: Connecting mind, research and everyday experience," Nelson Education., 2010.

[23] D. M. Misch, "McKeachie's Teaching Tips: Strategies, Research, and Theory for College and University Teachers," Wilbert McKeachie, Marilla Svinicki (Eds.)., Wadsworth Publishing. 2011.

[24] S. Williams, "Using video clips to stimulate discussion," Faculty Focus., 2007, pp. 600857600851.

[25] N. I. Scagnoli, A. McKinney, J. Moore-Reynen, "Video lectures in eLearning," In Handbook of Research on Innovative Technology Integration in Higher Education., IGI Global. 2015, pp. $115-134$.

[26] B. A. Bottge, M. Heinrichs, S. Y. Chan, Z. D. Mehta, E. Watson, "Effects of video-based and applied problems on the procedural math skills of average-and low-achieving adolescents," Journal of Special Education Technology., 2003, pp. 5-22.

[27] R. B. Burns, "Study and stress among first year overseas students in an Australian university," Higher Education Research and Development., 1991, pp. 61-77.

[28] J. M. Fautch, "The flipped classroom for teaching organic chemistry in small classes: Is it effective?," Chemistry Education Research and Practice., 2015, pp. 179-186.

[29] J. Cain, E. P. Black, J. Rohr, "An audience response system strategy to improve student motivation, attention, and feedback," American Journal of Pharmaceutical Education., 2009, pp. 21.

[30] M. Russell, R. Carey, G. Kleiman, J. D. Venable, "Face-to-face and online professional development for mathematics teachers: A comparative study," Journal of Asynchronous Learning Networks., 2009, pp. 71-87. 